Tasova, M. and I. Naneli, Bolu ve Tokat İllerindeki Buğday Sap Atıklarının Enerji Potansiyel Değerlerinin Karşılaştırmalı Teorik Analizi. International Journal of Life Sciences and Biotechnology, 2019. 2(3): p. 136-144.

\title{
Bolu ve Tokat İllerindeki Buğday Sap Atıklarının Enerji Potansiyel Değerlerinin Karşılaştırmalı Teorik Analizi
}

\section{Muhammed Tasova ${ }^{1 *}$ Ismail Naneli $^{2}$}

\section{ÖZET}

Biyogaz enerjisi, artan küresel enerji talebinin karşılanması için atılan adımlardan olumlu etkilenmektedir. Bu sebeple ülkemizin sahip olduğu organik madde potansiyelinin fazla olması bu atıkların enerjiye dönüştürülme çalışmalarını da hızlandırmıştır. Bu çalışmada, Bolu ve Tokat illerinde bulunan buğday sap atıklarının biyokütle, biyogaz ve enerji potansiyel değerleri kıyaslanmıştır. Bolu ve Tokat illerine ait atık ve kuru madde potansiyelleri sirasiyla, 2827.03-6187.41 ton ve 2459.515444.92 ton olarak tespit edilmiştir. İlave olarak, elde edilebilecek uçucu kuru madde potansiyelinin 1345.76-5383.04 ton ve metan potansiyelinin 614.88$2459.519 \mathrm{CH}_{4} \mathrm{~kg}$ olduğu belirlenmiştir. Enerji potansiyellerinin ise 22135.6148447.39 MJ olarak bulunmuştur. Bolu ilindeki buğday sap atıklarından elde edilebilecek enerji potansiyelinin Tokat iline oranının ortalama \% 45.69 daha fazla olduğu tespit edilmiştir.

MAKALE GEÇMIŞ̦i

Geliş

29 May1s 2019

Kabul

21 Temmuz 2019

ANAHTAR KELIMELER

Buğday sap1, kuru madde, enerji potansiyeli, Bolu, Tokat

\section{A Comparative Theoretical Analysis of the Energy Potential Values of Wheat Straw Waste in Bolu and Tokat Provinces}

\begin{abstract}
Biogas energy is positively affected by the steps taken to meet the growing global energy demand. For this reason, the potential of the organic matter of our country is high and the efforts to transform these wastes into energy have also gained momentum. In this study, biomass, biogas and energy potential values of wheat straw wastes in Bolu and Tokat provinces were compared. Wet waste weight and dry matter potentials of Bolu and Tokat provinces were determined as 2827.03-6187.41 tons and 2459.515444.92 tons respectively. However, the potential for volatile dry matter obtained was found to be 1345.76-5383.04 tons and the methane potential was $614.88-2459.519 \mathrm{CH}_{4}$ $\mathrm{kg}$. Energy potentials were found to be 22135.61-48447.39 MJ. In Bolu province, the ratio of energy potential obtained from wheat straw wastes found to be $45.69 \%$ higher than Tokat province.
\end{abstract}

\section{ARTICLE HISTORY}

Received

29 May 2019

Accepted

21 July 2019

\author{
KEY WORDS \\ Wheat straw, dry \\ matter, energy \\ potential, Bolu, Tokat
}

\section{Giriş}

Nüfus artışıyla birlikte enerji tüketim değerlerinin de aynı doğrultuda artış gösterdiği bilinmektedir. Günümüzde enerji üretiminde ham madde kaynağı olarak yoğunlukta fosil

\footnotetext{
${ }^{1}$ Tokat Gaziosmanpaşa Üniversitesi Ziraat Fakültesi Biyosistem Mühendisliği Bölümü/Tokat

${ }^{2}$ Tokat Gaziosmanpaşa Üniversitesi Ziraat Fakültesi Tarla Bitkileri Bölümü/Tokat

*Sorumlu yazar: muhammed.tasova@gop.edu.tr
} 
kökenli (kömür, doğalgaz, petrol) yakıtlar kullanılmaktadır. Rezerv ile tüketim miktarları kıyaslandığında fosil yakıtların hızla tükendiği ve gelecekte enerji ihtiyacını karşılayamayacağı belirtilmektedir. Bu sebeple fosil yakıtlara alternatif olarak kullanılan yenilenebilir enerji kaynaklarına yapılan yatırımların arttırılması ve üretim kaynaklarının daha etkin kullanılmasıyla bu durumun aşılacağı ön görülmektedir [1]. Yenilenebilir enerji kaynakları arasında yer alan biyokütle enerjisi hızlı bir şekilde gelişmekte ve yaygınlaşmaktadır. Biyokütle enerjileri (biyogaz, biyodizel, biyoalkol) içerisinde de biyogazın popülerliği her geçen gün artmaktadır.

Biyogaz, organik kökenli atıkların fermantatif ortamda farklı süreçlerden geçirilmesiyle üretilebilen bir enerji kaynağıdır [2-4]. Üretilen biyogaz saf bir gaz olmayıp, içeriğinde yaklaşık olarak \% 55- 75 oranında metan $\left(\mathrm{CH}_{4}\right)$, \% 25-45 oranında karbondioksit $\left(\mathrm{CO}_{2}\right)$, \% 1-10 oranında hidrojen $\left(\mathrm{H}_{2}\right)$, \% 0-0.3 oranında azot $\left(\mathrm{N}_{2}\right)$ ve \% 0-3 oranında ise hidrojen sülfür gazı $\left(\mathrm{H}_{2} \mathrm{~S}\right)$ bulunmaktadır [3-4]. Küresel boyutta, enerji tüketimde kullanım oranı her ne kadar sınırlı olsa da mevcut büyük potansiyelinden dolayı her zaman alternatif bir enerji kaynağı olarak güncel kalmıştır [5-7]. Avrupa ülkelerinde özellikle de Almanya gibi tarım sektöründe gelişmiş ülkeler biyokütle atıklarından elde ettiği biyogaz enerjisini (1S1, elektrik) işletmelerinde kullanarak maliyetleri azalmaktadır.

Bu bağlamda biyogaz kullanımı; üretim aşamalarında ham madde kaynağı olarak organik atıkların kullanılması, su kaynaklarının korunmasını sağlaması, kötü koku ve hastalık oluşumunun engellenmesi gibi çevresel avantajlarda sağlamaktadır [7]. Ülkemizde yıllık ortalama 50-65 milyon ton eş değer petrol (TEP) bitkisel ve hayvansal atık potansiyeli olduğu, bahsedilen değerin ortalama $\% 82$ oranını bitkisel atıkların oluşturduğu bilinmekte, atıkların enerji potansiyeli Türkiye'nin yıllık enerji tüketim değerinin yaklaşık \% 22-27'sine denk olduğu belirtilmektedir [8-9].

Bu durum özellikle Türkiye gibi tarımsal potansiyeli yüksek olan ülkelerin, organik atıkları daha verimli bir şekilde kullanarak biyokütle enerjisine dönüştürmesini gerektirmektedir. Biyokütle enerjisinin ham maddesini bitkisel, hayvansal, evsel atıklar ve belediye atıkları oluşturmaktadır. Atıklar genellikle toprak altına gömülmekte ya da doğrudan yakılarak en verimsiz şekilde kullanılmaktadır. Organik kökenli atıkların farklı prensip ve metotlarla biyogaz enerjisi elde edilip daha yarayışlı formlara dönüştürülme 
yollarına gidilmesi gereklidir. Ülkemizin önemli seviyede tarımsal atık potansiyeline sahip olması ve bu atıkların biyogaz enerjisi üretiminde kullanıldığı takdirde ülke ekonomisine büyük katkılar sağlayabileceğini gösterir [10]. Aybek ve ark. (2015)'nın yapmış oldukları çalışmada, ülkemizdeki hayvansal ve kullanılabilir bitkisel sap atıklarından elde biyogaz potansiyelinin yılda 331860 PJ olduğunu ortaya koymuştur [11]. Organik kökenli atıkların enerji potansiyellerinin belirlenmesi konusunda literatürde birçok benzer çalışma yapılmıştır [12-18]. 2018 yılında yapılan bu çalışmada ise Tokat ve Bolu illerindeki mevcut kullanılabilir buğday sap atıklarının, kuru madde, uçucu kuru madde, metan gazı ve enerji potansiyelleri belirlenerek karşılaştırılmıştır.

\section{Materyal ve Metot}

\section{Enerji potansiyelinin belirlendiği alanlar}

Çalışma kapsamında Bolu ve Tokat illerinin kullanılabilir buğday sap atıklarının teorik biyokütle, biyogaz ve enerji potansiyellerinin analizi yapılmıştır.

\section{Tokat ili}

Tokat ili Orta Karadeniz kıyılarını İç ve Doğu Anadolu Bölge'lerine bağlayan önemli bir noktadadır. Kuzeyinde Samsun, kuzeydoğusunda Ordu, güneyinde Sivas, güneybatısında Yozgat, batısında ise Amasya illeri ile çevrili olan Tokat'in toplam yüzölçümü 10071 km²'dir. Türkiye topraklarının yaklaşık \% 1.3'ünü kapsamaktadır [19].

Tokat ilinin tarım arazisi, orman, çayır-mera ve tarım dışı alan dağılımları büyüklükleri (ha) ve oluşturdukları \%'lik oranları tablo 1'de verilmiştir.

Tablo 1. Tokat ili toplam arazi dağılımı

\begin{tabular}{|l|c|c|}
\hline Arazinin türü & Yüz ölçümü (ha) & Toplam araziye oranı (\%)* \\
\hline Tarıma elverişli alan & 358139 & 35.56 \\
\hline Orman alanı & 443438 & 44.03 \\
\hline Çayır-mera alanı & 120036 & 11.92 \\
\hline Tarım dışı alan & 85587 & 8.50 \\
\hline Toplam & $\mathbf{1 0 0 7 ~ 2 0 0}$ & $\mathbf{1 0 0 . 0 0}$ \\
\hline *: Hesaplanan değerler & \multicolumn{2}{|l}{} \\
\hline
\end{tabular}

Tablo 1'e göre, Tokat ili arazi dağılımında en büyük alan \% 44.03 ile ormanlar oluştururken, en küçük alan ise \% 8.50 oran ile tarım dışı alanlar teşkil etmektedir. 


\section{Bolu ili}

Türkiye yüzölçümünün ortalama \% 1'lik kısmını oluşturan ve yüz ölçümü 8276 km² (827 600 ha) ile Karadeniz Bölgesi'nin Batı Karadeniz bölümünde yer almaktadır. Ortalama rakım seviyesi $1000 \mathrm{~m}$ olan Bolu ilinin batısında Düzce ve Sakarya, güneybatısında Bilecik ve Eskişehir, güneyinde Ankara, doğusunda Çankırı, kuzeyinde Zonguldak ve kuzey doğusunda ise Karabük İlleri yer almaktadır [20].

Bolu ilinin tarım arazisi, orman, çayır-mera ve tarım dışı alan dağılımları büyüklükleri (ha) ve oluşturdukları \%'lik oranları tablo 2'de verilmiştir.

Tablo 2. Bolu ili toplam arazi dağılımı

\begin{tabular}{|l|c|c|}
\hline Arazinin türü & Yüz ölçümü (ha) & Toplam araziye oranı (\%) $^{*}$ \\
\hline Tarıma elverişli alan & 149664 & 17.68 \\
\hline Orman alanı & 471514 & 55.71 \\
\hline Çayır-mera alanı & 124440 & 14.70 \\
\hline Tarım dışı alan & 100820 & 11.91 \\
\hline Toplam & $\mathbf{8 4 6} \mathbf{4 3 8}$ & $\mathbf{1 0 0 . 0 0}$ \\
\hline
\end{tabular}

*: Hesaplanan değerler

Tablo 2'ye göre, Bolu ili arazi dağılımında en büyük payı \% 55.71 ile ormanlar oluştururken, en küçük payı ise \% 11.91 ile tarım dışı alanlar teşkil etmektedir.

\section{Buğdayın çalışma alanlarındaki yetiştirilme miktarları (da)}

2017 yılında, Tokat ve Bolu ili ve ilçeler bazında yetiştirilen buğdayın ekim alanları tablo 3'de verilmiştir.

Tablo 3. İlçeler bazında buğday ekim alanları [21]

\begin{tabular}{|c|c|c|c|}
\hline TOKAT/İlçeler & dekar (da) & BOLU/İlçeler & dekar (da) \\
\hline Almus & 27680.00 & Dörtdivan & 60000.00 \\
\hline Artova & 47364.00 & Gerede & 100000.00 \\
\hline Başçiftlik & 19470.00 & Göynük & 67000.00 \\
\hline Erbaa & 136060.00 & Kibriscik & 4250.00 \\
\hline Merkez & 72626.00 & Mengen & 12900.00 \\
\hline Niksar & 169847.00 & Merkez & 130180.00 \\
\hline Pazar & 22140.00 & Mudurnu & 79367.00 \\
\hline Reşadiye & 65504.00 & Seben & 25677.00 \\
\hline Sulusaray & 43640.00 & Yeniçağa & 30000.00 \\
\hline Turhal & 224062.00 & & \\
\hline Yeşilyurt & 15552.00 & & \\
\hline Zile & 393357.00 & & \\
\hline Toplam & 1237311.00 & Toplam & 509374.00 \\
\hline
\end{tabular}

Tablo 3'te ilçelere göre, verilen ekim alan değerleri kullanılarak ortalama biyokütle potansiyeli belirlenirken, buğday bitkisi için toplanabilir değer olarak \% 15 oran baz alınmıştır [22]. Atıklardan elde edilebilecek kuru madde, uçucu kuru madde ve metan 
gazı potansiyelleri Sharma ve ark. (1988) tarafindan kullanılan yönteme göre hesaplanmıştır [23]. Uçucu kuru madde değerleri belirlenirken literatürdeki gerekli parametreler kullanılmıştır. Atıklardan elde edilebilecek metan gazının enerji değeri ise Aybek ve ark. (2015)'nın yapmış oldukları çalışmadaki yönteme göre tespit edilmiştir [11].

$A P=(((E A x 37 \times 15) / 100) 1000)$

Burada;

$A P$, buğday atık miktarı potansiyeli (ton/yıl); $E A$, buğday ekim alanı (da).

$K M=((A P x 88) / 100)$

Burada;

$K M$, Elde edilebilir kuru madde potansiyeli (ton/y1l).

$U K M=((A P x 87) / 100)$

Burada;

$U K M$, Uçu kuru madde potansiyeli (ton/y1l).

$\ddot{O} M O=U K M x 0.25$

Burada;

ÖMO, Özgül metan oranı $\left(\mathrm{CH}_{4} \mathrm{~kg}\right)$.

$M E=\ddot{O} M O \times 36$

Burada;

$M E$, Elde edilebilir metan gazının enerji değeri (MJ).

\section{Bulgular ve Tartışma}

Atık ve kuru madde potansiyeli

Tokat ve Bolu illerine ait yıllık ortalama buğday atık ve kuru madde potansiyelleri hesaplanmıştır (Tablo 4). 
Tablo 4. Attk ve kuru madde potansiyeli

\begin{tabular}{|l|c|c|l|c|c|}
\hline TOKAT/İlçeler & $\begin{array}{c}\text { Atık miktarı } \\
\text { (ton/yl) }\end{array}$ & $\begin{array}{c}\text { Kuru madde } \\
\text { (ton/yl) }\end{array}$ & BOLU/İlçeler & $\begin{array}{c}\text { Atık miktarl } \\
\text { (ton/yl) }\end{array}$ & $\begin{array}{c}\text { Kuru madde } \\
\text { (ton/yl) }\end{array}$ \\
\hline Almus & 153.62 & 135.19 & Dörtdivan & 333.00 & $\mathbf{2 8 9 . 7 1}$ \\
\hline Artova & 262.87 & 231.33 & Gerede & 555.00 & $\mathbf{4 8 2 . 8 5}$ \\
\hline Başçiftlik & 108.06 & 95.09 & Göynük & 371.85 & $\mathbf{3 2 3 . 5 1}$ \\
\hline Erbaa & 75.51 & 66.45 & Kıbriscık & 23.59 & $\mathbf{2 0 . 5 2}$ \\
\hline Merkez & 403.07 & 354.71 & Mengen & 71.60 & $\mathbf{6 2 . 2 9}$ \\
\hline Niksar & 962.65 & 829.53 & Merkez & 722.50 & $\mathbf{6 2 8 . 5 7}$ \\
\hline Pazar & 122.88 & 108.13 & Mudurnu & 440.49 & $\mathbf{3 8 3 . 2 2}$ \\
\hline Reşadiye & 363.55 & 319.92 & Seben & 142.51 & $\mathbf{1 2 3 . 9 8}$ \\
\hline Sulusaray & 242.20 & 213.14 & Yeniçağa & 166.50 & $\mathbf{1 4 4 . 8 6}$ \\
\hline Turhal & 1243.54 & 1094.32 & & & \\
\hline Yeşilyurt & 86.31 & 75.96 & & & \\
\hline Zile & 2183.13 & 1921.16 & & & \\
\hline Toplam & $\mathbf{6 1 8 7 . 4 1}$ & $\mathbf{5 4 4 4 . 9 2}$ & Toplam & $\mathbf{2 ~ 8 2 7 . 0 3}$ & $\mathbf{2 4 5 9 . 5 1}$ \\
\hline
\end{tabular}

Tablo 4'e göre, Tokat'ın ilçeleri arasında buğday atıklarından elde edilebilecek en fazla kuru madde potansiyeli 1921.16 ton ile Zile ilçesinde tespit edilmiş olup, Bolu ilinde ise en fazla 628.57 ton ile merkez ilçede tespit edilmiştir. Tokat-Bolu il ve ilçelerinde belirlenen buğday sap atıklarından elde edilebilir uçucu kuru madde ve özgül metan potansiyelleri tablo 4'te verilmiştir.

\section{Uçucu kuru madde ve özgül metan potansiyeli}

Tablo 4'te verilen atık ve kuru madde potansiyel değerleri kullanılarak ortalama uçucu kuru madde ve özgül metan değerleri hesaplanmıştır (Tablo 5).

Tablo 5. Uçucu kuru madde ve özgül metan potansiyeli

\begin{tabular}{|l|c|c|l|c|c|}
\hline \multicolumn{1}{|c|}{ TOKAT/İlçeler } & $\begin{array}{c}\text { Uçucu kuru } \\
\text { madde } \\
\text { (ton/yll) }\end{array}$ & $\begin{array}{c}\text { Özgül metan } \\
\left(\mathbf{C H}_{\mathbf{4}} \mathbf{~ k g}\right)\end{array}$ & BOLU/İlçeler & $\begin{array}{c}\text { Uçucu kuru } \\
\text { madde } \\
\text { (ton/yl) }\end{array}$ & $\begin{array}{c}\text { Özgül metan } \\
\left(\mathbf{C H}_{\mathbf{4}} \mathbf{~ k g}\right)\end{array}$ \\
\hline Almus & 133.65 & 33.41 & Dörtdivan & 289.71 & 72.43 \\
\hline Artova & 288.70 & 57.17 & Gerede & 482.85 & 120.71 \\
\hline Başçiftlik & 94.01 & 23.50 & Göynük & 323.51 & 80.88 \\
\hline Erbaa & 65.70 & 16.42 & Kibrisck & 20.52 & 5.13 \\
\hline Merkez & 350.67 & 87.67 & Mengen & 62.29 & 15.57 \\
\hline Niksar & 820.11 & 205.03 & Merkez & 628.57 & 157.14 \\
\hline Pazar & 106.90 & 26.73 & Mudurnu & 383.22 & 95.81 \\
\hline Reşadiye & 316.29 & 79.07 & Seben & 123.98 & 31.00 \\
\hline Sulusaray & 210.72 & 52.68 & Yeniçağa & 144.86 & 36.21 \\
\hline Turhal & 1081.88 & 270.47 & & & \\
\hline Yeşilyurt & 75.09 & 18.77 & & & \\
\hline Zile & 1899.32 & 474.83 & & & \\
\hline Toplam & $\mathbf{5 3 8 3 . 0 4}$ & $\mathbf{1 3 4 5 . 7 6}$ & Toplam & $\mathbf{2 4 5 9 . 5 1}$ & $\mathbf{6 1 4 . 8 8}$ \\
\hline
\end{tabular}

Tablo 5'e göre, Tokat'ın ilçeleri arasında buğday atıklarından elde edilebilecek en fazla uçucu kuru madde ve özgül metan potansiyel değerleri sirasıyla 1889.32 ve 474.83 ton 
ile Zile ilçesinde belirlenmiştir. En az ise, Erbaa ilçesinde olup sırasıyla, 65.70 ve 16.42 ton olarak bulunmuştur. Bolu ilinde ise en fazla merkez ilçede tespit edilmiş olup sırasıyla, 628.57 ve 157.14 olarak hesaplanmıştır. Tokat-Bolu il ve ilçelerinde belirlenen metan gazının enerji potansiyelleri ise tablo 6' da verilmiştir.

\section{Metan gazının enerji potansiyeli}

Tablo 5'te verilen elde edilebilir metan gazı değerleri kullanılarak enerji potansiyelleri belirlenmiştir (Tablo 6).

Tablo 6. Enerji potansiyelleri

\begin{tabular}{|l|c|l|c|}
\hline TOKAT/İlçeler & Enerji potansiyeli (MJ) & BOLU/illçeler & Enerji potansiyeli (MJ ) \\
\hline Almus & 1202.88 & Dörtdivan & 2607.39 \\
\hline Artova & 2058.27 & Gerede & 4345.65 \\
\hline Başçiftlik & 846.10 & Göynük & 2911.59 \\
\hline Erbaa & 591.27 & Kibriscık & 184.69 \\
\hline Merkez & 3156.07 & Mengen & 560.59 \\
\hline Niksar & 7380.06 & Merkez & 5657.17 \\
\hline Pazar & 962.13 & Mudurnu & 3449.01 \\
\hline Reşadiye & 2846.57 & Seben & 1115.83 \\
\hline Sulusaray & 1896.44 & Yeniçağa & 1303.70 \\
\hline Turhal & 9736.95 & & \\
\hline Yeşilyurt & 675.84 & & $\mathbf{2 2 ~ 1 3 5 . 6 1}$ \\
\hline Zile & 17093.92 & & \\
\hline Toplam & $\mathbf{4 8 4 4 7 . 3 9}$ & Toplam & \\
\hline
\end{tabular}

Tablo 6'ya göre, Tokat'ın ilçeleri arasında buğday atıklarından elde edilebilecek en fazla enerji potansiyeli 17 093.92 MJ ile Zile ilçesinde olduğu en az ise, 591.27 MJ ile Erbaa ilçesinde tespit edilmiştir. Bolu ilinde ise en fazla 5 657.17 MJ ile merkez ilçede olup en az ise 184.69 MJ ile Kıbrıscık ilçesinde belirlenmiştir. Bolu ilinde belirlenen buğday sap atıklarından elde edilebilir enerji potansiyeli Tokat ilindeki enerji potansiyelinin ortalama \% 45.69'u olduğu hesaplanmıştır. Elde edilen sonuçlar Tokat ilinin buğday sap atıkları enerji potansiyelinin Bolu ili enerji potansiyelinden yüksek olduğunu göstermektedir. Demir (2018)'in Kars ilinin biyokütle ve enerji potansiyelini araştırdığg çalışmasında, toplam biyokütle potansiyelinin 1558794 ton/yıl olduğu, belirtilen kaynaklardan yılda $76913077 \mathrm{~m}^{3}$ biyogaz elde edilebileceğini ifade etmiştir [24]. Deniz ve ark. (2015)'nın yapmış oldukları çalışmalarda ülkemizdeki meyve suyu, bitkisel yağ ve et endüstrisi atık miktarlarının toplam 118 milyon ton civarında olduğu, bahsedilen atıklardan ise ortalama 25.3 milyar $\mathrm{m}^{3}$ biyogaz elde edilebileceğini ifade etmiştir [25]. Alibaş ve ark. (2015), yaptıkları çalışmada Diyarbakır iline ait buğday, mısır, çeltik, arpa, soya, çavdar, 
şekerpancarı ve darı gibi bitki atıklarından elde edilebilecek biyogaz potansiyelini 827.42 milyon $\mathrm{m}^{3} / \mathrm{y} 1$ olarak tespit etmişlerdir [26].

\section{Sonuç ve Öneriler}

Çalışmada, Tokat ve Bolu illerine ait kullanılabilir buğday sap atıklarına göre elde edilebilecek yıllık ortalama atık, kuru madde, uçucu kuru madde, metan ve enerji potansiyelleri araştırılmıştır. Belirlenen bulgular doğrultusunda Tokat ilinde ortalama 48447.39 MJ'lük ve Bolu ilinde ise ortalama 22135.61 MJ'lük bir metan gazı enerji potansiyelinin olduğu görülmüştür. Enerji açığımızın azaltılması konusunda ülke çapında mevcut buğday sap atıklarından elde edilebilecek enerji potansiyellerinin uygulamaya aktarılmasının önemli olacağı düşünülmektedir.

\section{Kaynaklar}

1 Yüksel T. and Esen M., Elazığ İli İçin Çeşitli Yenilenebilir Enerji Kaynaklarının Deneysel Olarak Değerlendirilmesi. Doğu Anadolu Bölgesi Araştırmalar Dergisi, 2010.

2 Weiland P. Biogas Production: Current State and Perspectives, Applied Microbiology and Biotechnology, 2010, 85: 849-860.

3 Şanlıurfa Karacadağ Kalkınma Ajansı, Kompost Tesisi Kurulması Amacına Yönelik Fizibilite Çalışması Projesi Kapsamında Hazırlanan Kompost ve Biyogaz Tesisi Fizibilite Raporu. 2014. https://www.karacadag.gov.tr/Dokuman/Dosya/www.karacadag.org.tr 9 GE0Y40BF_kompost tesisi_kurulmasi_amacina_yonelik_fizibilite_calismasi.pdf (Erişim Tarihi:25.05.2019).

4 Şenol, H., et al., Türkiye’de Biyogaz Üretimi İçin Başlıca Biyokütle Kaynakları. Bitlis Eren Üniversitesi Fen Bilimleri Dergisi, 2017. 6(2), 81-92.

5 El-Mashad, HM., et al., Effect of temperature and temperature fluctuation on thermophilic anaerobic digestion of cattle manure. Bioresource Technol., 2004. 95: 191-201.

6 Zaher, U., et al., Evaluation of a new fixed-bed digester design utilizing large media for flush dairy manure treatment. Bioresource Technol., 2008. 99: 8619-8625.

7 Dede, Ö.H., et al., Hayvansal Atıklardan Biyogaz Üretimi İçin Küçük Ölçekli Reaktör Modeli Geliştirilmesi. Karaelmas Fen ve Mühendislik Dergisi, 2018. 8(1):138-146.

8 Tafdrup, S., Centralized Biogas Plants Combine Agricultural and Environmental Benefits with Energy Production, Water Science and Technology, 1994. 30:133-140.

9 Çağlayan, G.H. and Koçer, N.N., Muş İlinde Hayvan Potansiyelinin Değerlendirilerek Biyogaz Üretiminin Araştırılması. Muş Alparslan Üniversitesi Fen Bilimleri Dergisi, 2014. 2(1), 215-220.

10 Ekinci, K., Kulcu, R., Kaya, D., Yaldız, O., Ertekin, C., The Prospective of Po-tential Biogas Plants That Can Utilize Animal Manure in Turkey. Energy Exploitation and Exploration. 2010. 28 (3), 187-206.

11 Aybek, A., et al., Türkiye'de kullanılabilir Hayvansal Gübre ve Tahıl Sap Atıklarının Biyogaz ve Enerji Potansiyelinin Belirlenerek Sayısal Haritalarının Oluşturulması. Tekirdağ Ziraat Fakültesi Dergisi. 2015. 12 (03). 111-120.

12 Büyük, G., et al., Adıyaman İlinin Hayvansal Atık Kaynaklı Vermikompost Üretim Potansiyeli. ADYÜTAYAM, 2017. 5(2), 31-37. 
13 Türkmenler, H., et al., Zeytin küspesi çözeltisinin derişime bağlı biyogaz ve hidrojen potansiyelinin incelenmesi. Adıyaman Üniversitesi Mühendislik Bilimleri Dergisi, 2018. 5(8), 147-155.

14 Karaman, S.,et al., Tokat İlinin Hayvansal Atık Kaynaklı Biyogaz Enerjisi Potansiyeli ve Uygulanabilirliği. Bahri Dağdaş Hayvancılık Araştırma Dergisi, 2015. 4 (2), 11-19.

15 Taşova, M., Yerel bir küçükbaş hayvancılık işletmesi'nin biyogaz potansiyelinin belirlenmesi. Türk Tarım ve Doğa Bilimleri Dergisi, 2018. 5(3),268-272.

16 Taşova, M. and Ergüneş, G., Determination of Biomass Potential and Energy Values of Walnut (Juglans regia L.) Wastes: Case of Tokat Province. International Scientific and Vocational Studies Journal, 2018. 2(2), 67-72.

17 Scarlat, N., et al., A spatial analysis of biogas potential from manure in Europe. Renewable and Sustainable Energy Reviews, 2018. 94, 915-930.

18 Zareei, S., Evaluation of biogas potential from livestock manures and rural wastes using GIS in Iran. Renewable Energy, 2018. 118, 351-356.

19 Anonim, 2019a. Tokat (il), https://tr.wikipedia.org (Erişim Tarihi: 21.05.2019).

20 Anonim, 2019b. Bolu, https://tr.wikipedia.org (Erişim Tarihi: 21.05.2019).

21 Türkiye İstatistik Kurumu (TÜİK), Konularına göre istatistikler, www.tuik.gov.tr (Erişim Tarihi: 20.05.2019).

22 Öztürk, H. H. and Başçetinçelik, A., Energy exploitation of agricultural biomass potential in Turkey. Energy Exploration and Exploitation Dergisi, 2006. 24 (5), syf: 313-330.

23 Sharma, et al., Effect of particle size on biogas generation from bimass residues. Biomass, 1988. 17 (4): 251-263.

24 Demir, M., Kars ilinin biyokütle enerji potansiyeli ve kullanılabilirliği. Türk Coğrafya Dergisi, 2018. 68, 31-41.

25 Deniz, et al., Türkiye'de Gıda Endüstrisi Kaynaklı Biyokütle ve Biyoyakıt Potansiyeli. Gıda Dergisi, 2015. 40(1): 47-54. doi: 10.15237/gida.GD14037.

26 Alibaş,et al., Diyarbakır İlinin Tarımsal Kaynaklı Biyogaz Pota siyelinin Belirlenmesi. Tarım Makineleri Dergisi, 2015. 11 (1). 75-87. 